\title{
QUÉ EFICACIA Y PARA QUÉ JUSTICIA (A PROPÓSITO DE NUESTRO SISTEMA PUNITIVO)
}

Perfecto ANDRES IBAÑEZ

Vocal del Consejo General del Poder Judicial

(*) Texto de la ponencia presentada por el autor al Congreso extraordinario de la Asociación Profesional de la Magistratura, celebrado en Madrid los días 10-13 de febrero de 1983, sobre el tema "Justicia eficaz". 



\section{Dos lecturas para un lema.}

Para un observador ajeno que careciera de toda otra referencia, la simple noticia de un colectivo de magistrados autoconvocándose en torno al lema Justicia eficaz sería seguramente evocadora de algo más que una gozosa celebración festiva de las excelencias de la actual coyuntura de la función y del oficio. aunque sólo fuera por lo que ya a una simple aproximación superficial en términos de lenguaje corriente sugiere la proppia semántica de los términos empleados.

Si el hipotético observador fuese un cierto español de a pie que captara el "flash" informativo desde un mínimo de civil interés por los problemas del entorno, vería con toda probabilidad en los convocados o reunidos a un grupo de jueces justamente (valga la redundante expresión) preocupados por el statu quo de un área de la institucionalidad estatal que a la conciencia de la gente de hoy más que arcano comienza a aparecer caótico.

Desde una perspectiva menos "laica» es casi seguro que la elección como tema de debate-es decir, en clave al menos eventualmente interrogativa-de la calidad que en este caso se toma de entre las que pudieran (afirmativa o negativamente) predicarse de la justicia-servicio públi$c o$, no dejaría de producir cierta sorpresa. Porque la voz eficacia en el diccionario remite a efecto, que puede ser, también según el diccionario, "bueno" o "malo», o "deplorable», o "desastroso", y que en última instancia viene de hacer. $Y$ no se nos negará que en el contexto de una concepción sacral de la justicia, ampliamente generalizada y compartida-sobre todo intra-muros de palacio-casi hasta la fecha, y de la que permanecen visibles supervivencias litúrgicas y no sólo, no habría el menor espacio para preguntas o actitudes capaces de implicar el más leve cuestionamiento o duda, desde luego incompatible con el carisma de la actividad(1). Todo ello en virtud de una lógica de auto-preservación, que es en último término la que recorre el sistema por cuya estabilidad tal cual debe velar entre otros el aparato judicial.

Lo intuía muy bien un viejo magistrado, personaje de SCIACIA: "...cuando una religión comienza a tener en cuenta la opinión laica, está bien muerta, aún sin saberlo. Y lo mismo la justicia. La ad́ministración de justicia....s(2). 
Pues bien, es claro que preguntarse abiertamente acerca de la eficacla o no de algo o alguien que antes estaba fuera o por encima de discusión, aparte su carga de sano "laicismo" comporta un cambio de perspectiva. O quizás mejor de horizonte con a su vez, por lo menos, dos perspectivas posibles. No necesariamente excluyentes por principio, pero que suelen darse en el marco de discursos netamente diferenciados y políticamente contrapuestos.

Puesto que hablamos de perspectivas, diríase apurando el símil óptico que en el fondo del asunto late una cuestión previa de "enfoque». Porque puede gustarnos basicamente lo que hay, sin perjuicio incluso de admitirlo perfectible, y ello llevará a nuestro esfuerzo a concentrarse en «un más acáan de racionalización y mejora en la mecánica de un aparato bueno en si, pero cuyo rendimiento medido en unidades del mismo "producto» debe, sin embargo, aumentarse. $O$ bien, por el contrario, puesto que la eficacia es un valor instrumental, la estimación insatisfactoria del nivel de la calidad de aquel, conducirá necesariamente a la demanda de un cambio en los propios elementos constitutivos del "sistema productivo». Porque, no nos engañemos, se produce aquello y sólo aquello para lo que se tiene aptitud, para lo que se está preparado.

Dos son pues, en síntesis, las actitudes que cabe mantener frente a una cuestión como la que nos ocupa. A partir del acuerdo básico en la constatación ya tópica de que la justicia vive una grave situación de crisis, falla el consenso cuando se trata de diagnosticar su etiología y determinarse a propósito de las eventuales salidas. Para unos-¿los más?-todo se reduce a una cuestión de medios; a la resolución de un problema técnico abordable por la vía de la pura recualificación funcional de estos aparatos. Otros estiman-estimamos-que lo que se entiende como uel problema» (endémico, no se olvide) debe ser tomado por indicador. Es fundamentalmente un síntoma que remite a regiones y responde a razones más profundas del complejo institucional y está bien lejos de admitir verdaderas soluciones en una clave puramente eficientista.

Por decirlo esquemáticamente: ¿estamos ante un simple-aunque grave-desajuste susceptible de solución dentro de la propia economía del sistema? ¿Se da una inadecuación "patológica" reversible y tratable 
exclusivamente en el plano instrumental, o por el contrario todo ello es expresión de una forma de coherencia "fisiológica" en la relación medios/fines, que evoca una consciente opción valorativa?.

Una larga serie de datos, muchos accesibles a la observación superficial, autorizan a pensar que no es por casualidad que esta justicia es como es y hace lo que hace. Por no hablar de lo que no hace.

2. El actual sistema punitivo: su significación.

Para el punto de vista tradicional, hasta la fecha dominante y desde luego "de sentido común" en la materia, el conjunto de instituciones enmarcadas en lo que se conoce como "sistema penal»(3) tenía por cometido el tratamiento de las disfuncionalidades más llamativas producidas en el interior de un cuerpo social esencialmente sano.

Sin embargo, la observación de que determinadas ciencias sociales han hecho objeto al área de la justicia penal, ese complejo de instituciones que va de la ley a la cárcel pasando por la policía y por el juez, ha abierto camino a una impresión bien diferente. Para CHAPMAN, por ejemplo, el sistema judicial tiene como función la de «crear criminalesw(4).

Aparato de control social por excelencia ejerce una tarea complementaria, aunque esencial en el marco de todo un cúmulo de dispositivos cuyo objetivo mediato sería asegurar el mantenimiento y la reproducción del orden imperante, velar por la conservación de este estado de cosas en sus mismos téminos. Traducir determinados fenómenos del antagonismo social a formas tolerables de conflictividad individualizada.

Por eso, se dice, su eficiencia es fundamentalmente criminalizadora y se desarrolla a través de un cuidadoso proceso francamente selectivo que-para atenernos a los límites de lo que aquí nos interesa-comienza ya en la misma configuración del tipo penal y desemboca, aunque no acaba, en la cárcel.

No es posible ignorar que en nuestra sociedad, y más en la presente situación de crisis, acceder al status de delincuente es algo que está 
mucho más al alcance de unas que no de otras categorias de personas, $Y$ ello en función de presupuestos esencialmente arbitrarios (no gratuitos) en cuanto expresión de una previa elección valorativa en el plano de la politica penal: se protegen más o menos determinados intereses, ubicados en determinadas regiones del sistema. Por eso, el mismo CHAPMAN ha escrito que, en muchos casos, «si se prescinde del factor de la condena, no hay diferencias entre criminales y no criminalesw(5).

Algo que no porque pueda sonar a escandaloso deja de ser meridianamente claro si se compara el sospechoso celo con que ese tratamiento se escatima a quienes atentan desde las alturas de la pirámide social contra la fiscalidad del Estado y otros fundamentales intereses colectivos y la prodigalidad con que se dispensa a quienes-en virtud de una dinámica de apropiación de lo ajeno esencialmente equivalente-se llevan, al fin y al cabo "el chocolate del loro". Aún cuando como suele suceder se haya puesto previamente a estos últimos en una situación que tantas veces les bloqueaba toda otra posibilidad alternativa.

Nuestras leyes e instituciones son tan implacables con los muchachos del "mono", los del "tirón" o del "cassette» (y desde luego no estoy por la justificación sin más de estas conductas), como ridícula y sospechosamente impotentes frente a conocidas actividades de depredación económica a gran escala o de corrupción administrativa en perjuicio de todos(6).

Por eso puede decir BARATTA que "la criminalidad, más que un dato preexistente, descubierto objetivamente por las instancias oficiales, es una realidad social de la que éstas últimas son elemento constitutivo. Porque constituyen tal realidad social a través de una percepción selectiva de los fenomenos, que se traduce en el reclutamiento de una circunscrita población criminal seleccionada de entre la más amplia franja de aquellos que ejecutan acciones previstas por las leyes penales y que comprendiendo todos los sectores sociales, representa no la minoría sino la mayoría de la poblacións(7).

De esta manera se hace evidente que la ley penal-por acción y no menos por omisión-ejerce un trato netamente diferencial en el momento previo de tipificar o no determinadas conductas desviadas. Por otra parte, 
conocidos estudios sociológicos(8) han puesto de manifiesto también como los cuerpos policiales encuentran a los delincuentes precisamente donde les buscan, mientras existen auténticas zonas de inmunidad, sobre todo en ciertos estratos superiores de la sociedad.

¿Es concebible mayor situación de impotencia en cualquier sector del aparato estatal que la de un juez de instrucción (incluso juez "central») de este país con su miserable attrezzo frente a la complejidad y sofisticación de uno cualquiera de los grandes fraudes de que se tiene noticia?.

Habría que convenir, por tanto, que no le falta razón a DOMINIQUE CHARVET cuando valórando todos estos datos termina viendo a la institución judicial, de la que forma parte, como "garante, no de la aplicación de la ley a todos sino más bien de la exoneración de todo control legal de la actividad de algunosw(9).

\section{Política "penal" versus política "criminal".}

El actual grado de desarrollo de las ciencias sociales ha puesto claramente de relieve cómo un elevado porcentaje de las conductas criminalizadas tienen que ver directamente con las profundas desigualdades que recorren vertebralmente el sistema. (La sola intuitiva puesta en relación de las cifras del paro y las de la evolución de cierto tipo de delincuencia ahorran cualquier otro argumento). Esta circunstancia hace que la falta de una atención adecuada en sede política (si se da o no una incapacidad constitutiva sería otro tema) por parte de las instancias a las que correspondería la responsabilidad de remover (ahora incluso por imperativo constitucional) la raíz de las disfuncionalidades y contradicciones de que se nutre una porción sustantiva de las magnitudes de la criminalidad, convierte la respuesta penal no en la pretendida ultima ratio, sino en auténtica unica ratio muchas veces.

Siendo ésto muy grave lo sería algo menos si la "oferta» judicial y penitenciaria respondieran siquiera tendencialmente a la imagen que intentan proyectar de sí mismas. Pero lo cierto es que si de la primera cabe decir con fundamento lo que antes se ha expuesto, el fracaso de la cárcel 
como espacio de rehabilitación y resocialización es ya un lugar común en cualquier discurso que no quiera ser burdamente mistificador(10).

Marginación social, criminalidad y represión carcelaria son realidades que se encuentran estrechamente inter-implicadas en una especie de relación de circularidad. En la inmensa mayoría de los casos la primera de aquellas variables está en la base de la delincuencia primaria, que resulta ulteriormente reforzada a partir de la segregación que la prisión impone. A la marginación básica se añade una suerte de sobre-marginación institucional que hace que la única adaptación posible sea la que realmente se da al propio medio carcelario y todo lo que significa. Está tristemente demostrado que la influencia de la experiencia institucional sobre el udesviado primarion se traduce èn compulsión efectiva a organizar su vida futura en torno al hecho mismo de la desviación. Es el afianzamiento en el camino de lo que los criminólogos Ilaman bien graficamente "carrera criminals(11), de la que un paso fundamental, constitutivo cabría decir, es la ínteriorización por el sujeto de los modelos de comportamiento propios de la subcultura carcelaria.

"Pero-son palabras de GEORGE JACKSON, escritas desde la cárcel, desde su condición de negro encarcelado en un penal americano ${ }^{\circ}$ ¿qué podemos decir de estos asilos de los que ningún interno sale curado? Al contrario, salen de la prisión más dañados física y mentalmente que cuando entraron. Esa es la realidad. Tal como están las cosas ¿continuarías investigando al interno o te preguntarías donde comienza la responsabilidad administrativa? s(12).

La irracionalidad puede adquirir connotaciones ciertamente dantescas cuando en ese medio, inhumano en el mejor de los casos, se producen situaciones como las que, por ejemplo, relata el Ministerio Fiscal en su escrito de conclusiones provisionales en la causa seguida en la Audiencia Provincial de Ciudad Real contra doce funcionarios del establecimiento de alta seguridad de Herrera de la Mancha(13). Y ya, en el límite, cuando la institución de "máxima seguridad» hacia el exterior, no garantiza e incluso pone directamente en peligro la supervivencia física de los internos, como puede deducirse de la elevada tasa de suicidios(14). 
Hay que añadir que, como es bien sabido, la privación de libertad en un número altamente significativo de los casos, tiene carácter preventivo más yue formalmente penal. Resulta por todo ello difícil no compartir el juicio de FERRAJOLI cuando se refiere a esa "paradoja institucional" de «una comunidad confiada al control total del Estado, pero en cuyo interior no rige control ni regla alguna sino la ley del más fuerte (...) una sociedad artificial, producida por el derecho que es al propio tiempo sociedad natural sin reglas y sin derechos, donde revive el "homo homini lupus" (...) un aparato coercitivo, máxima expresión del poder del Estado sobre el ciudadano, pero en cuyo interior el Estadó está ausente: y no el Estado de derecho, sino simplemente el Estado en su acepción hobbesiana, capaz de asegurar la vida y la incolumidad personalw(15).

Todo lo expuesto justifica a nuestro entender que entre nosotros no quepa hablar de otra cosa que de política penal y ejercida en condiciones tales que hacen de ella un potente factor criminógeno, un potente factor de multiplicación y reforzamiento de los fenómenos que supuestamente se trataría de erradicar.

Unà adecuada política criminal exigiría como presupuesto previo la clara toma de conciencia de las limitaciones e insuficiencias de la respuesta punitiva, y de la necesidad de su reducción a la condición de efectiva ultima ratio dentro de un riguroso sistema de garantías. Al,mismo tiempo, la puesta en ejercicio de una clara estrategia de transformación social e institucional orientada a remover desde el fondo las condiciones que hacen del fenómeno criminal algo perteneciente a la "normalidad" del orden establecido y que sólo puede ser efectivamente abordado en una rigurosa perspectiva de cambio.

4.- Incidencia de la falta de una adecuada política criminal en el papel del juez penal.

La falta hasta la fecha (en el plano intencional incluso) de una política criminal adecuada da lugar a que la punitiva sea la única respuesta institucional a toda una serie de fenómenos, fundamentalmente radicados en las capas marginales de esta sociedad. 
Así, complejísimas situaciones sociales resultan tratadas de modo exclusivamente represivo y de forma totalmente inadecuada pensando en lo que exigiría su eventual erradicación.

Los tipos penales se configuran, como es bien sabido, abstrayendo determinados datos de una secuencia de comportamientos reales socialmente dados. Tales variables pasan a ser así jurídicamente relevantes y consideradas merecedoras de reproche en su conjunto, lo que supone la virtual irrelevancia en principio a esos efectos de todas las demás. De cuáles sean unas y otras dependerá el sentido de la eficacia del precepto y de su proyección práctica.

Pues bien,por poner un ejemplo tomado de la más mordiente cotidianeidad, nuestras leyes penales, - las de un país que carece en absoluto del mínimo de preocupación institucionalizada en materia de prevención y no digamos ya asistencia a la drogadicción-, prescinden con absoluta tranquilidad de conciencia de datos como: $1 .^{\circ}$ que el «síndrome de abstinencian por falta de la dosis precisa de determinadas drogas duras ejerce tal compulsión en quien lo padece como para hacer inútil en el plano de la prevención especial cualquier medida penal; $2 .^{\circ}$ que el "consumidor-puro", el único teóricamente impune, no tiene realidad estadísticamente relevante, siendo por el contrario arquetípico el adicto que precisa ejercer un mínimo de «tráfico" para sustentar el propio consumo.

De este modo, la carencia de una atención efectiva al problema en las sedes administrativas en que el mismo debiera afrontarse, unida a una legislación que choca abiertamente con el dato sociológico, producen el resultado de poner en manos de la justicia la tarea sucia (y vana) de contener mal-tratando el crecimiento del número de personas que encarnan un género de "delincuenćia» que en su estado actual sólo puede explicarse merced a la decișiva aportación causal del propio sistema. Semejante divorcio entre la realidad y el orden punitivo lleva a la diaria criminalización de indivíduos gravemente enfermos de cuya dramática situación personal al parecer sólo interesa el dato penalizado que constituye puramente el síntoma de todo un síndrome del que friamente se hace abstracción. 
Por otra parte, por vía de interpretación jurisprudencial puede llegarse a situaciones de corte tan inequívocamente surrealista como la de que la "liberalidad consistente en brindar varias chupadas de cigarrillo de "hachis" supone no sólo la donación a que se refiere el art. 344 del Código Penal, sino además "acto de iniciación en el consumo, equivalente y subsumible en el 'promover' legal...'(16). Esto sobre el fondo de una sịtuación social en que cerca de un $50 \%$ de los jóvenes comprendidos en edades entre los 15-20 años ha hecho uso del "porro", que precisamente se fuma pasándolo entre quienes lo comparten(17). Y en un momento en que «la cannabis ha dejado de ser una droga contestataria y contracultural, si es que en algún momento lo fue, $y$ al igual que en otros países occidentales ha pasado a ocupar un rango de cotidianeidad encontrándose en todos los ambientes: burguesía, profesiones liberales y técnicos, estudiantes, proletariado y lumpenproletariado, no revistiendo su consumo mayor significación que la de facilitar una cierta evasión edonistaw(18).

Con ésto quiere decirse-y el anterior es un único ejemplo pero suficientemente ilustrativo-que en ausencia de una verdadera política criminal el juez se verá siempre inevitablemente constreñido a desempeñar una función de suplencia regresiva. A contener coactivamente dentro de los límites de lo tolerable las consecuencias de lo que no se hace en las instancias del sistema primariamente encargadas de prevenir. o evitar, removiendo sus antecedentes conocidos, mucho de lo que ulteriormente termina por ser injustamente criminalizado. A producir auténticos uchivos expiatorios" sobre los que proyectar las insuficiencias y las culpas de esta sociedad, que encuentra así un factor adicional de cohesión de sus miembros "sanos" frenta a quienes no lo están(19).

Las situaciones de crisis como las que actualmente vivimos tienen la dudosa virtud de ofrecer en clave expresionista la confirmación de lo que se viene diciendo. O lo que es lo mismo: cuanto mayor y más cruel es la desigualdad, mayor también la necesidad de control social. Cuando más patente se hace la ausencia de justicia en las relaciones sociales, más penetrante y necesaria resulta la presencia represiva de la justicia como institución. 
5. Sobre el actual sistema punitivo de nuestro país.

En la Memoria elaborada por el Consejo General del Poder Judicial en 1981, podía leerse textualmente: «No es que la justicia como organización sea mala o buena, adecuada o inadecuada, es que 10 hay empresan(20), elidiéndose prudentemente con esa fórmula de recio sabor tecnocrático el no hay justicia que, por imperativo de coherencia exigía el mismo contexto.

No cabe aquí una referencia pormenorizada a los distintos planos que integran lo que hemos llamado nuestro sistema punitivo. Pero sí al menos sugerir esquemáticamente las notas más relevantes desde el punto de vista de lo que nos interesa. Al mes de diciembre de 1982 puede afirmarse en síntesis que:

1. ${ }^{\circ}$ En el orden legislativo es evidente la presencia de un verdadero movimiento "descodificador", utilizando la conocida expresión de IRT/(21), que se concreta en la dispersión de fuentes normativas penal-procesales, con quiebra de su unidad sistemática y notorias inconsecuencias en el plano de los principios informadores. Desde el punto de vista procedimental se constata una abierta ruptura con la línea garantista que inspiraba nuestra Ley de Enjuiciamiento Criminal de 1882(22). Desde el ángulo propiamente penal puede pensarse en la quiebra de, entre otros, el principio de legalidad que comportan disposiciones como, por poner sólo un ejemplo, el art. 1 del Real Decreto-ley de 26 de enero de 1979 sobre protección de la seguridad ciudadana.

2. Leyes como la Orgánica 11/1980, de 1 de diciembre, sobre los supuestos previstos en el art. 55.2. ${ }^{\circ}$ de la Constitución, hacen aún más simbólico el carácter de judicial de las fuerzas de policía de este país. Y al mismo tiempo, como no podía ser de otro modo, confinan con demasiada frecuencia a la administración de justicia en el papel mecánicamente legitimador de lo actuado autónomamente por esa instancia del ejecutivo. Esto llega al colmo en aquellos casos en que es la propia policía quien por sí misma decide cuándo debe prescindir del juez.

3. ${ }^{\circ} \quad$ También el ejecutivo se reserva el control directo del Ministerio Fiscal, cuya reorganización relativamente democrática en que según sus mentores habría de traducirse la puesta en práctica del nuevo Estatuto, viene demorándose de forma evidente. 
4. La disfuncionalidad del servicio judicial llega al punto de que, sencillamente, no sólo es que los ciudadanos desconfien de la justicia, es que el juez es el primero que no puede creerselo. Porque faltan los mínimos ( $y$ ya hemos visto que no sólo «empresariales») para dar cumplimiento a las exigencias que en este ámbito plantea la autodefinición de un Estado como «social y democrático de derecho". La justicia judicial en un país democrático sólo puede decirse existente a partir de determinados presupuestos que aquí todavía no se dan. Me atrevería a decir por eso que, si quisiera recuperarse el vocablo para poder referirlo en un futuro deseable, sin despertar ecos demasiado penosos en la memoria de las gentes, a una institución profundamente renovada, valdría la pena pensar en dejar de someterlo al desgaste que supone su reiteradamente acrítica y tópica asociación a aquella en su actual situación.

A quien pueda parecerle ésto exagerado le invitaría al esfuerzo necesario para tratar de vivir imaginativamente la experiencia desde "la piel del justiciablew(23). Del de todos los días, de ese que, prescindiendo aunque sea mucho prescindir del dato pre-procesal, de "lo irrelevante" para el derecho, pasa sin asistencia letrada en su detención. Se ratifica en lo declarado, pero nunca ante el juez y fácilmente sin haber leido lo que tiene suscrito con su firma. Ingresa sin saber muy bien hasta cuando en prision preventiva en virtud de una resolución «standard". $O$, en el mejor de los caos, quedando en libertad se ve obligado a acudir repetidas veces al juzgado por extrañas exigencias de un procedimiento llamativamente «arítmicon. Tiene un abogado de oficio al que no conoce. Que tal vez presta su conformidad a la calificación del fiscal sin haber cambiado con su "cliente" una palabra. Aunque con un poco de suerte pudieran encontrarse en los pasillos unos minutos antes del juicio, uno o tal vez más años después de aquellos hechos...

En la otra cara de la medalla la evidencia no menos real y recurrente en la práctica del ingente volumen de conductas que desde sectores privilegiados de esta sociedad violan gravemente las leyes penales en situación de verdadera impunidad. Y para cuyos autores, cuando a pesar de todo topan con la justicia, las cosas discurren de muy distinta forma, al menos en lo que a costes humanos se refiere. 
6. Acerca de la eficacia represiva de esta justicia.

Si las presentes consideraciones se abren con el doble interrogante que les sirve de título, es por que ésta que para muchos es ya justicia, a mi al menos me parece ya terriblemente eficaz. ¿De qué clase de eficacia?.

En la respuesta que creo ha de darse a esta pregunta, veo la clave de la situación actual de nuestro sistema punitivo. De la permanencia de esa situación que si por algo se caracteriza es precisamente por su tremeda incidencia represiva.

¿Cabe mayor exasperación de la reacción punitiva que la que supone trasladar en bloque los momentos de prevención e intimidación propios de la pena al proceso penal en sí mismo?.

Si el proceso penal es uno de los momentos de verdad de la consistencia democrática de un sistema político, el principio de presunción de inocencia a su vez representa el verdadero banco de pruebas de la calidad del primero.

Los autores consideran que la presunción de inocencia tiene un significado plural: es regla de tratamiento del imputado y a la vez regla de juicio. En el primer sentido, señala NOBILI, se refiere a la condición de imputado y en particular a su libertad personal; en el segundo afecta al sector de las pruebas y de la decisión sobre el hecho, como criterio para la adquisición del material probatorio y de su valoración(24).

De este modo, donde el principio tenga efectiva vigencia, como dice gráficamente VALIANTE, en ausencia de una condena definitiva, el sujeto a quien se impute un delito es igual a todos los demás, debe poder gozar de la estima de todos y, antes aún, de la del Estado(25). Y, por otra parte, se dará una eficaz actuación del imperativo de inmediatividad, como previa exigencia de una adecuada obtención y apreciación del material probatorio.

No parece difícil ilustrar hasta qué punto todo esto es por hoy ajeno a nuestra realidad procesal.

Vigente sí la presunción de inocencia al amparo del art. 24 de la Constitución, que no es poco, también es cierto que ha dado lugar a interesan- 
tes prácticas jurisprudenciales, sobre todo y primero del Tribunal Constitucional. Pero la normalidad estadística va por otros derroteros.

Piénsese a ese respecto en el carácter regular con que debe aplicarse la prisión preventiva a partir de la vigencia de los arts. 503 y siguientes de la Ley de Enjuiciamiento Criminal en su nueva redacción(26). Y en la perpetuación de las situaciones de privación de libertad en que se traduce el tremendo deterioro de la maquinaria judicial. Sin contar con el gravamen adicional que supone el deplorable estado de los centros de detención...

En el segundo aspecto son de destacar las escasas posibilidades que nuestro juez penal tiene de producir o de orientar siquiera por sí mismo la prueba. De manera que al contradictorio apenas le queda otro sentido que el puramente ritual, en vista de la importancia y el peso de la actividad instructora, de matiz policial en gran mediad.

No debe resultar extraña por tanto la sistemática proyección de la "reforma de la justicia» en ese futuro sin tiempo, tedioso lugar común de abundante y conocida literatura ministerial. Al fin y al cabo ¿dónde los eternos beneficiarios del actual (casi eterno) estado de cosas iban a encontrar un modelo procesal-penal con mayor funcionalidad a su oscuro proyecto?.

Es por lo que creo que, como he dicho, solo desde unos presupuestos políticos diferentes puede proyectarse una justicia distinta.

Unos presupuestos políticos que demanda la propia vigente Constitución democrática en su apuesta clara por la efectividad real de los derechos fundamentales de la persona.

\section{Por una nueva eficacia para una justicia distinta.}

Lo hasta aquí expuesto lleva por necesidad a cuestionarse con carácter previo a cualquier opción instrumental el modelo de justicia que se quiere para propiciar desde él un cierto tipo de eficacia.

Desde luego se admite que la mejora de las condiciones materiales de la actual administración de justicia supondría un avance que no puede 
subestimarse. Pero ya se ha dicho, y a ello nos remitimos, por que hay razones para pensar que no es por casualidad que al modelo de justicia propia de este sistema le ha correspondido desde siempre ese peculiar género de eficaz-ineficacia.

Por eso se estima que la salida de tal viejo círculo vicioso pasa por una previa clara opción política en el terreno de los valores. Por la exigencia de un cambio de cualidad en las relaciones sociales y profundas transformaciones en el tejido institucional.

Sería presuntuoso apuntar "soluciones", pero sí cabe formular ciertas exigencias prioritarias de inaplazable ejecución, por las que tendría que pasar una política de la justicia al servicio de la democracia. Sin ánimo de exhaustividad, desde luego, podrían avanzarse los siguientes:

1. Una profunda reconsideración de los bienes jurídicos merecedores de protección penal y de su jerarquía relativa a la luz de la Constitución. Consistiendo la sanción penal en una privación de derechos que son fundamentales de la persona, es evidente que su aplicación sólo puede tener lugar cuando ello resulte impuesto por la relevancia constitucional de los bienes de cuya protección se trate.

2. Ya dentro del ámbito propiamente penal, debe atenderse prioritariamente a la tutela de determinados intereses de primario carácter social: la salud, el medio ambiente, la economía pública, el trabajo...

3. En la misma línea y como contrapartida, urge proceder a la despenalización de determinadas conductas. Con carácter puramente ilustrativo podría pensarse en cuestiones como la interrupción voluntaria del embarazo, drogas blandas, opinión, tráfico automovilístico, etc. A tal efecto habría que tener en cuenta la evolución experimentada por los modelos culturales vigentes en nuestro país, así como determinadas experiencias legislativas de otros como Alemania e Italia.

4. ${ }^{\circ}$ Deberá ponerse inmediato remedio a aquellos problemas de la actual administración de justicia que tienen más directamente que ver con su miseria material. Simultáneamente habrá de afrontarse la reforma del procedimiento, atendiendo a aspectos como: 
a) Fortalecimiento de la gestión directa del juez durante todo el proceso.

b) Disponibilidad real de la policía.

c) Ampliación de la incidencia del principio acusatorio.

d) Recuperación para el plenario de su carácter de verdadero juicio y con ello de la oralidad y contradicción como condiciones esenciales.

c) Modificación de la regulación actual de la prisión preventiva, que sólo podrá imponerse por tiempo limitado, previa valoración judicial del caso concreto y por razones de estricto carácter procesal.

f) Dar efectividad a la asistencia letrada al detenido a lo largo de todo el procedimiento y desde la detención policial.

g) Hacer igualmente efectiva la gratuidad de la justicia, sin que ello repercuta en la calidad de la defensa.

5. No menos urgente parece la apertura de cauces realmente practicables a la opinión pública en el interior de la institucionalidad judicial. El conocimiento fundado de la verdadera dimensión y naturaleza de los problemas es paso necesario para suscitar una demanda social cualitativamente distinta y no fácilmente manipulable, como lo viene siendo hasta ahora desde las "ideologías del orden" y en clave de puro reduccionismo represivo. No será demasiado fácil, pero habrá de conseguirse que el hombre de la calle sustituya por una actitud crítica y comprensiva de la completa etiología de los fenómenos estudiados la habitual propensión a hacer cuestion de orden público y tratable sólo punitivamente cualquier forma de desviación.

6. Probada hasta la saciedad la terrible realidad y nulas posibilidades humanizadoras de la cárcel, y puesto que esta sociedad no parece por el momento capaz de prescindir de ella, se impone limitar su aplicación a lo indispensable, modificando absolutamente su situación y potenciando la respuesta en práctica de fórmulas alternativas y modalidades atenuadas de internamiento.

Una reflexión serena, pública y abierta por parte de los profesionales de todos los ámbitos implicados e interesados en las cuestiones aborda- 
das, con amplia participación social, es no obstante el mejor camino para abrir vías a una auténtica superación del presente estado de cosas. Serviría además para poner en marcha una dinámica capaz de evitar en el futuro la separación y el aislamiento que han sido el mejor caldo de cultivo de un caos en que la justicia apenas puede reconocerse.

Mientras eso no tenga lugar, una tremenda hipoteca continuará pesando sobre aspectos fundamentales de nuestra vida civil. Porque, para decirlo con palabras de PELLEGRINO ROSSI, de incuestionable vigencia: "La libertad política tiene particular necesidad de la justicia; ambas son dos condiciones sociales inseparables entre sí. Cuando una de ellas ha existido durante un trasncurso de tiempo, la otra nace necesariamente; $y$ si alguna llega a faltar, la otra tarda poco en desaparecer o en ser desnaturalizadaw(27).

\section{NOTAS:}

(1) Me refiero a esa vieja concepción mítica de la justicia que mientras proyectaba todo lo relacionado con ésta en las esferas de lo inefable y fuera del alcance de cualquier planteamiento crítico, cerraba los ojos a bien evidentes formas de control político. Arquetípico es al respecto el Discurso leido por el Ministro AUNOS en al acto de apertura de tribunales de 1943 (Ed. Reus, Madrid 1943, vid. especialmente pp. 44 y ss.).

Expresivas consideraciones en la misma línea pueden encontrarse en DE MIGUEL, Jaque a la justicla, Barcelona 1980, pp. 43 y ss. entre otras. Propugna el autor ael abandono de los cuadros judiciales si existe incorporación a una ideología activa cualquiera». (op. cit. pp. 44).

(2) I/ contesto, Torino, 5. a edición 1979, p. 87.

(3) Cfr. sobre el particular P. ROBERT/C. FAUGERON, La justice et son public. Les representations sociales du systeme pénal. Genève 1978, pp. 45 y ss.

(4) Lo stereotipo criminale, trad. R. Palmiteri, Torino 1971, p. 7.

(5) Op. cit., p. 6.

(6) "...los cinco expedientes remitidos al fiscal sobre actuaciones de bancos que pudieran ser constitutivos de delito suelen quedar paralizados cuando llegan a manos del correspondiente juez instructor». ("Malestar en el Banco de España», Tiempo de hoy, 29 de noviembre de 1982. Para un tratamiento sumamente riguroso y pormenorizado del tema, puede verse C. VILADAS JENE, Los delitos de quiebra: norma jurídica y realidad social, Barcelona 1982, entre otras, pp. 263 y ss. 
(7) Criminologia critica e critica del diritto penale, Bologna 1988,.p. 181.

(8) Cfr. J. YOUNG, "Polizziotti e drogati», Comunità, n. ${ }^{\circ}$ 168, XII 1972.

(9) "¿Crisis de la justicia, crisis de la ley, crisis del Estado?" en La crisis del Estado, Ed: de N. Poulantzas, trad. de S. Vilar, Barcelona 1977, p. 305.

(10) Cfr. F. MUÑOZ CONDE, "La resocialización del delincuente, análisis y crítica de un miton, en La Reforma del derecho penal, Ed. a cargo de S. MIR, Barcelona 1980, vol. I, pp. 61 y ss.

(11) Sobre este tema vid. por todos R. BERGALLI, La recalda en el delito: modos de reaccionar contra ella, Barcelona 1980, especialmente pp. 267 y ss.

(12) En Soledad Brother. Cartas de prisión, trad. J. Freyre, Barcelona 1971, p. 65.

(13) Vid. El País de 27 de julio de 1982. sobre este "affaire» M. REVUELTA, Herrera de la Mancha. Una historia ejemplar, Madrid 1980.

(14) Cfr. "Muertes en la cárcel», El País, 10 de julio de 1982. "Otra muerte en Carabanchel», id. 21 de julio de 1982.

(15) "Carcere e diritti fondamentalin, en Questione giustizia, 12, 1982, pp. 358-359.

(16) Tribunal Supremo, Sala 2. ${ }^{a}$, ss. 25 de enero de 1980, 11 de febrero de 1980, 2 de julio de 1980 , entre otras.

(17) Cfr. La población española ante las drogas, Documentación social, n. ${ }^{\circ} 42$ (monográfico) enero-marzo 1981, p. 111.

(18) "Cannabis", de SOLE INSA, SOLE PUGG, SAN MOLINA, BERNARDO, en Toxicomanias. Un enfoque multidisciplinar, de varios autores, Barcelona 1981, p. 189.

(19) Cfr. P. ROBERT/C. FAUGERON, op. cit.

(20) Memoria elaborada por el Consejo General del Poder Judicial sobre el estado de la justicia en 1981, Boletín de Información número extraordinario, julio de 1981, p. 29.

(21) L'età della decodificazione, Milano 1979.

(22) He desarrollado este tema en "Cien años después. Lo que queda de la Ley de Enjuiciamiento Criminal», Poder Judicial, septiembre 1982, n. ${ }^{\circ} 4$, pp. 41 y ss.

(23) Tomo la expresión del título de la obra de J. LIBMANN, La peau du justiciable, Paris 1979.

(24). La presunzione d'innocenza dell'imputato, Bologna 1979, p. 15.

(25) II novo processo penale, Milano 1975, p. 160.

(26) "La Ley 16/80, de 22 de abril que modificó los artículos de la Ley de Enjuiciamiento Criminal en lo relativo a la prisión provisional, determinó un aumento muy importante del número de internos en situación de preventivos", Consejo General del Poder Judicial, Memoria, Madrid 1982, p. 87.

(27) Tratado de derecho penal, trad. de C. Cortés, 2. ${ }^{a}$ ed. Madrid 1872, tomo primero, p. 13. 